\title{
Clinical Application of the Main Viral Proteinase (Mpro or 3clpro) Inhibitors for Coronavirus Therapy
}

\author{
Abhinav Kanwal ${ }^{*}$ and Shailendra Pratap Singh ${ }^{2 *}$ \\ ${ }^{1}$ Department of Pharmacology, All India Institute of Medical Sciences, Bathinda, Punjab 151001, India \\ ${ }^{2}$ Department of Biomedical Engineering, School of Engineering and Technology, Central University of Rajasthan, India
}

*Corresponding author: Shailendra Pratap Singh, Assistant Professor, Department of Biomedical Engineering, School of Engineering and Technology, Central University of Rajasthan, Bandarsindri, Kishangarh, Ajmer, Rajasthan, 305817, India

Abhinav Kanwal, Assistant Professor, Department of Pharmacology, All India Institute of Medical Sciences Bathinda, Punjab 151001, India

\section{ARTICLE INFO}

Received: 幽 September 01, 2020

Published: 㓞 September 15, 2020

Citation: Abhinav Kanwal, Shailendra Pratap Singh. Clinical Application of the Main Viral Proteinase (Mpro or 3clpro) Inhibitors for Coronavirus Therapy. Biomed J Sci \& Tech Res 30(3)-2020. BJSTR. MS.ID.004944.

\begin{abstract}
The whole world is running behind the coronavirus and coronavirus running around the globe. In this situation, it is a matter of time to develop new immediate medicine to cure these pandemics, as we are aware that vaccines will take lots of time to come into functioning. In this situation, we need to have a drug that can inhibit the spreading of this virus and treat the patient in different ways. Clinical trials are currently investigating the use of various compounds and targets to treat SARS-CoV-2 infection. There are no clinically approved antiviral drugs, vaccines, or monoclonal antibody therapies to treat SARS-CoV infections. Moreover, the continued development of therapeutic and prophylactic countermeasures to potentially deadly coronaviruses is warranted. The coronaviral proteases, specially 3C-like protease (Mpro or 3CLpro), are attractive antiviral drug targets because they are essential for coronaviral replication. Although the Mpro or 3CLpro inhibitor compounds are to process the viral polyprotein. Therefore, targeting Mpro or 3CLpro with inhibitors may have an advantage in not only inhibiting viral replication but also inhibiting the dysregulation of signaling cascades in infected cells that may lead to cell death in the surrounding, uninfected cells. The inhibition of SARS-CoV Mpro or 3CLpro inhibitor compounds, and the prospect of inhibiting papainlike protease from other coronaviruses. Mpro or 3CLpro inhibitor compounds opens the door in the quick treatment of Antiviral therapy against this highly pathogenic human coronavirus."
\end{abstract}

\section{Introduction}

The world is suffering from a pandemic of Severe acute respiratory syndrome coronavirus 2 (SARS-CoV-2), which was ruined in Wuhan (China) and consequently spread worldwide. Several members of the family Coronaviridae continuously circulate in the human population and frequently produce mild respiratory disease [1]. SARS-CoV and another Middle East respiratory syndrome coronavirus (MERS-CoV) are transmitted from animals to humans and instigate severe respiratory diseases in afflicted individuals, SARS, and MERS, respectively [2]. SARS-COV emerged in 2002 in Guangdong province, China, and its subsequent global spread will be associated with 8,096 cases and 774 deaths [2-5]. The Chinese horseshoe bats serve as natural reservoir hosts for SARS-CoV [6,7]. Infection in a human will be transmitted by different intermediate carriers, i.e., raccoon dogs, civet cats, and other animals, which are frequently sold as food sources in Chinese wet markets [6]. There is no specific medicine, drug, vaccine, or therapy to stop the spread and treat the SARS. Furthermore, and the SARS pandemic in 2002 and 2003 will be finally ended by 
conventional control measures, including travel restrictions and patient isolation.

It started in December 2019; a new infectious respiratory disease emerged in Wuhan, Hubei province, China [7,8]. The starting of infections will be linked to the Huanan seafood market, potentially due to animal contact. Consequently, human-tohuman transmission happened, and the disease, currently termed coronavirus disease 19 (COVID-19), quickly blowout to a country like China, USA, and Europe and further spread to the whole world. This SARS-coronavirus 2 has a close relation to SARS-CoV, which has been detected in many patients, and all can trust to have the same etiologic agent of the new lung disease [9-11]. On February 12,2020 , a total of 44,730 laboratory-confirmed infections will be reported in China, including 8,204 [12].

\section{Discussion}

A novel coronavirus has been identified as the causative agent of severe acute respiratory syndrome (SARS). The viral main proteinase (Mpro, also called 3CLpro), which controls the activities of the coronavirus replication complex, is an attractive target for therapy. The role of Mpro or 3CLpro has already proven to be a valuable target in drug discovery efforts and has been validated as a valid drug target in several studies. It has even been termed "the Achilles' heel of coronaviruses" [13]. A wide variety of inhibitor classes, including peptidomimetic analogs, covalent Mpro or 3CLpro inhibitors, and small molecule inhibitors, have been assessed. These compounds have been identified by ab initio structure-based design, high throughput, and virtual screening $[13,14]$, where inhibitors either target the enzyme active site or the allosteric dimerization domain $[15,16]$. The first generation of Mpro or 3CLpro inhibitors will be irreversible peptidomimetic structures, often five residues in length with at reactive warhead at the terminus that formed a covalent bond between the thiolate anion of the catalytic Cys145 residue and the reactive atom of the warhead [17]. These reactive warheads have included Michael acceptors, aldehydes, epoxy-ketones, halo-methyl ketones, and trifluoromethyl ketones. The development of Mpro or 3CLpro inhibitors later followed peptide derivative warhead inhibitors However, the use of covalent inhibitors is limited due to their propensity for off-target side-effects and toxicity [18-27]. Recent studies have therefore focused more on the development of noncovalent inhibitors, which have generally produced abundant peptidomimetic compounds with low ligand efficiency [17] and currently, there is still no effective therapy for the treatment of HCV [12].

All coronavirus Mpro or 3CLpro share high sequence homology and interior chain architecture and substrate conservation [28,29], which makes the identification of broad-spectrum lead compounds more viable. The substrate-binding site of the Mpro or 3CLpro has two deeply buried S1 and S2 subsites, as well as shallow S1', S3, and S4 subsites holding different solvent treatment angles. The specificity of the Substrate related to coronavirus Mpro or 3CLpro is mainly determined by the $\mathrm{P} 1, \mathrm{P} 2$, and $\mathrm{P} 1$ ' positions [29]. The Glutamine is found at the P1 location precisely; it makes hydrogen bond between S1 subsite and imidazole Nع2 of His162/3 and van der Waals interactions to the residues of the $\mathrm{S} 1$ active pocket. Furthermore, the P2 position prefers leucine or methionine to fill the hydrophobic S2 pocket. The S3 site sidechains are solventexposed, which, and this position is expected to tolerate a wide range of functionality, shows a preference for basic residues [30]. Sidechains and backbones of residues surrounding the S4 site create a highly congested pocket, which favors a small, hydrophobic residue in the P4 position, either Ser, Thr, Val, or Pro [31-32]. The $\mathrm{S}^{\prime}{ }^{\prime}$ and $\mathrm{S} 2^{\prime}$ subsites also accommodate small residues in the $\mathrm{P} 1^{\prime}$ and $\mathrm{P} 2$ ' positions, which may include Ser, Ala or Gly [31,33]. The recognition position for cleavage has (Ser, Ala) -(Val, Thr)-Leu-Glu $\downarrow$ (Ser, Ala, Gly), which is conserved among all coronavirus Mpro or 3CLpro $[34,35]$. These features can, therefore, be exploited in the design of potential broad-spectrum significant compounds.

\section{References}

1. Corman VM, Lienau J, Witzenrath M (2019) Coronaviruses as the cause of respiratory infections. Internist (Berl) 60(11): 1136-1145.

2. Corman VM, Landt O, Kaiser M, Molenkamp R, Meijer A, et al. (2020) Detection of 2019 novel coronavirus (2019-nCoV) by real-time RT-PCR. Euro Surveill 25(3).

3. de Wit E, Van Doremalen N, Falzarano D, Munster VJ (2016) SARS and MERS: recent insights into emerging coronaviruses. Nat Rev Microbiol 14(8): 523-534.

4. Ding Y, He L, Zhang Q, Huang Z, Che X, et al. (2004) Organ distribution of severe acute respiratory syndrome (SARS) associated coronavirus (SARS-CoV) in SARS patients: implications for pathogenesis and virus transmission pathways. J Pathol 203(2): 622-630.

5. Fehr AR, Channappanavar R, Perlman S (2017) Middle East Respiratory Syndrome: Emergence of a Pathogenic Human Coronavirus. Annu Rev Med 68: 387-399.

6. Guan Y, Zheng BJ, He YQ Liu XL, Zhuang ZX, et al. (2003) Isolation and characterization of viruses related to the SARS coronavirus from animals in southern China. Science 302(5643): 276-278.

7. Huang C, Wang Y, Li X, Ren L, Zhao J, et al. (2020) Clinical features of patients infected with 2019 novel coronavirus in Wuhan (China: Lancet) 395(10223): 497-506.

8. Lau SK, Woo PC, Li KS, Huang Y, Tsoi HW, Wong BH, Wong SS

9. Leung SY, Chan KH, Yuen KY (2005) Severe acute respiratory syn- drome coronavirus-like virus in Chinese horseshoe bats. Proc. Natl Acad Sci USA 102(39): 14040-14045.

10. Zhou P, Yang XL, Wang XG, Hu B, Zhang L, et al. (2020) A pneumonia outbreak associated with a new coronavirus of probable bat origin. Nature 579: 270-273.

11. Zhu N, Zhang D, Wang W, Li X, Yang B, et al. (2020) A Novel Coronavirus from Patients with Pneumonia in China, 2019. N Engl J Med 382(8): $727-$ 733.

12. Lu R, Yu X, Wang W, Duan X, Zhang L, et al. (2012) Characterization of human coronavirus etiology in Chinese adults with acute upper respiratory tract infection by real-time RT-PCR assays. PLoS ONE 7(6): e38638. 
13. Yang H, Bartlam M, Rao Z (2006) Drug Design targeting the main protease, the Achilles heel of Coronaviruses. Curr Pharm Des 12(35): 4573-4590.

14. Barrila J, Bacha U, Freire E (2006) Long-range cooperative interactions modulate dimerization in SARS Mpro or 3CLpro. Biochemistry 45(50): 14908-14916.

15. Wei P, Fan K, Chen H, Ma L, Huang C (2006) The N-terminal octapeptide acts as a dimerization inhibitor of SARS coronavirus 3C-like proteinase. Biochem Biophys Res Commun 339(3): 865-872.

16. Ding L, Zhang XX, Wei P, Fan K, Lai L (2005) The interaction between severe acute respiratory syndrome coronavirus 3C-like proteinase and a dimeric inhibitor by capillary electrophoresis. Anal Biochem 343(1): 159-165.

17. Jacobs J, Grum Tokars V, Zhou Y, Turlington M, Saldanha SA, et al. (2013) Discovery, synthesis, and structure-based optimization of a series of $\mathrm{N}$-(tert-butyl)-2-(N-arylamido)-2-(pyridin-3-yl) acetamides (ML188) as potent noncovalent small molecule inhibitors of the severe acute respiratory syndrome coronavirus (SARS-CoV) 3CL protease. J Med Chem 56(2): 534-546.

18. Ghosh AK, Xi K, Ratia K, Santarsiero BD, Fu W (2005) Design and synthesis of peptidomimetic severe acute respiratory syndrome chymotrypsin-like protease inhibitors. J Med Chem 48(22): 6767-6771.

19. Yang S, Chen SJ, Hsu MF, Wu JD, Tseng CTK (2006) Synthesis, crystal structure, structure-activity relationships, and antiviral activity of a potent SARS coronavirus 3CL protease inhibitor. J Med Chem 49(16): 4971-4980.

20. Ghosh AK, Xi K, Grum Tokars V, Xu X, Ratia K (2007) Structure-based design, synthesis, and biological evaluation of peptidomimetic SARSCoV Mpro or 3CLpro inhibitors. Bioorg Med Chem Lett 17(21): 58765880.

21. Lee TW, Cherney MM, Liu J, James KE, Powers JC (2007) Crystal structures reveal an induced-fit binding of a substrate-like aza-peptide epoxide to SARS coronavirus main peptidase. J Mol Biol 366(3): 916-932.

22. Goetz D, Choe Y, Hansell E, Chen Y, McDowell M (2007) Substrate specificity profiling and identification of a new class of inhibitor for the major protease of the SARS coronavirus. Biochemistry 46(30): 87448752.

23. Zhang HZ, Zhang H, Kemnitzer W, Tseng B, Cinatl J (2006) Design and synthesis of dipeptidyl glutaminyl fluoromethyl ketones as potent

\section{ISSN: 2574-1241}

DOI: 10.26717/BJSTR.2020.30.004944

Abhinav Kanwal, Shailendra Pratap Singh. Biomed J Sci \& Tech Res

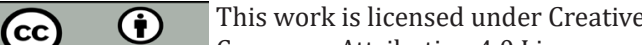

Commons Attribution 4.0 License

Submission Link: https://biomedres.us/submit-manuscript.php severe acute respiratory syndrome coronovirus (SARS-CoV) inhibitors. J Med Chem 49(3): 1198-1201.

24. Sydnes MO, Hayashi Y, Sharma VK, Hamada T, Bacha U (2006) Synthesis of glutamic acid and glutamine peptides possessing a trifluoromethyl ketone group as SARS-CoV 3CL protease inhibitors. Tetrahedron 62(36): 8601-8609.

25. Yang H, Yang M, Ding Y, Liu Y, Lou Z (2003) The crystal structures of severe acute respiratory syndrome virus main protease and its complex with an inhibitor. Proc Natl Acad Sci USA 100(23): 13190-13195.

26. Lu IL, Mahindroo N, Liang PH, Peng YH, Kuo CJ (2006) Structure-based drug design and structural biology study of novel nonpeptide inhibitors of severe acute respiratory syndrome coronavirus main protease. J Med Chem 49(17): 515-5161.

27. Guterman L (2011) Covalent drugs form long-lived ties. Chem. Eng News 89: 19-26.

28. Zhao Q, Li S, Xue F, Zou Y, Chen C (2008) Structure of the main protease from a global infectious human coronavirus, HCoV-HKU1. J Virol 82: 8647-8655.

29. Hegyi A, Ziebuhr J (2002) Conservation of substrate specificities among coronavirus main proteases. J Gen Virol 83(3): 595-599.

30. Chuck CP, Chow HF, Wan DCC, Wong KB (2011) Profiling of substrate specificities of $3 \mathrm{C}$-like proteases from group $1,2 \mathrm{a}, 2 \mathrm{~b}$, and 3 coronaviruses. PLoS ONE. 6: e27228.

31. Anand K, Ziebuhr J, Wadhwani P, Mesters JR, Hilgenfeld R (2003) Coronavirus main proteinase (Mpro or 3CLpro) structure: Basis for design of anti-SARS drugs. Science 300(5626): 1763-1767.

32. Xue X, Yu H, Yang H, Xue F, Wu Z, et al. (2008) Structures of two coronavirus main proteases: Implications for substrate binding and antiviral drug design. J Virol 82: 2515-2527.

33. Hsu MF, Kuo CJ, Chang KT, Chang HC, Chou CC (2005) Mechanism of the maturation process of SARS-CoV 3CL protease. J Biol Chem 280(35): 31257-31266.

34. Ziebuhr J, Snijder EJ, Gorbalenya AE (2000) Virus-encoded proteinases and proteolytic processing in the Nidovirales. J Gen Virol 81(4): 853-879.

35. Zhenming Jin, Xiaoyu Du, Yechun Xu, Yongqiang Deng, Meiqin Liu, et al. (2020) Structure of Mpro from COVID-19 virus and discovery of its inhibitors.

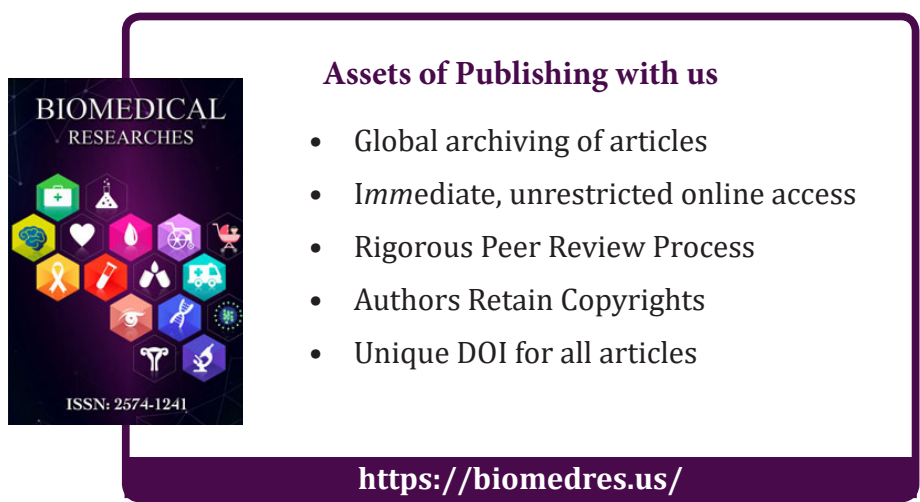

